\title{
An electrochemiluminescence biosensor for 8-oxo-7,8-dihydro-2'- deoxyguanosine quantification and DNA repair enzyme activity ana- lysis using a novel bifunctional probe
}

\author{
Yiping $\mathrm{Wu}^{\mathrm{a}, \mathrm{b}}$, Xiqiang Yang ${ }^{\mathrm{c}}$, Bintian Zhang ${ }^{\mathrm{a}}$, Liang-Hong Guo ${ }^{\mathrm{a}, *}$ \\ a State Key Laboratory of Environmental Chemistry and Ecotoxicology, Research Center for Eco-environmental Sciences, Chinese Academy of Sciences, Beijing \\ 100085, China \\ ${ }^{\mathrm{b}}$ The Education Ministry Key Lab of Resource Chemistry, Shanghai Key Laboratory of Rare Earth Functional Materials and Department of Chemistry, \\ Shanghai Normal University, Shanghai 200234, China \\ ${ }^{\mathrm{c}}$ Department of Chemical Engineering, Chengde Petroleum College, Chengde, Hebei 067000, China
}

\section{A R T I C L E I N F O}

\section{Article history:}

Received 4 December 2014

Received in revised form

13 February 2015

Accepted 25 February 2015

Available online 26 February 2015

Keywords:

Electrochemiluminescence sensor

Enzyme activity assay

Mercury

8-Oxo-7,8-dihydro-2'-deoxyguanosine

Formamidopyrimidine-DNA glycosylase

\begin{abstract}
A B S T R A C T
A new electrochemiluminescence (ECL) sensor was developed for 8-oxo-7,8-dihydro-2'-deoxyguanosine (8-oxodGuo) quantification and Escherichia coli formamidopyrimidine-DNA glycosylase (FPG) activity assay. The sensor employed a novel spermine conjugated ruthenium tris-(bipyridine) derivative (spermine-Ru) which binds specifically with 8-oxodGuo through a one-step reaction and also acts as an ECL signal reporter. In the sensor, an 8-oxodGuo-containing ds-DNA film was first immobilized on a gold electrode by self-assembly. The DNA film was then incubated with spermine-Ru under oxidative condition for 8-oxodGuo labeling. The ECL intensity was found to correlate with the amount of 8-oxodGuo on the surface and the detection limit was estimated to be about 1 lesion in 500 DNA bases. Addition of FPG resulted in some loss of the signal due to the excision of 8-oxodGuo by the enzyme. An inverse relationship between ECL intensity and FPG concentration was observed in a range from 0 to $4.0 \mathrm{U} / \mu \mathrm{L}$, demonstrating that this sensor could be used for FPG activity assay. A number of metal ions were screened by the sensor for their inhibition effect on FPG activity. Among them, $\mathrm{Hg}^{2+}$ and methyl $\mathrm{Hg}$ (II) shown very potent inhibition, with $\mathrm{IC}_{50}$ values of $4.04 \mu \mathrm{M}$ and $4.34 \mathrm{nM}$ respectively. The result may suggest that interference on the DNA repair system could be another mechanism for the high toxicity of MeHg.
\end{abstract}

(c) 2015 Elsevier B.V. All rights reserved.

\section{Introduction}

Oxidative DNA damage is an inevitable consequence of cellular metabolism, with a tendency of increasing levels under the invasion of toxic exogenous substances (Jackson and Loeb, 2001; Cooke et al., 2003; Halliwell, 1991; Valko et al., 2004). In numerous oxidatively damaged DNA products, 8 -oxodGuo has received the most extensive study. Accumulation of 8 -oxodGuo in bacterial and mammalian cells may lead to G:C to A:T transversion mutations and even cancerous tumors (Cheng et al., 1992; Andrew et al., 1996). In medical diagnosis, the level of urinary 8-oxodGuo has been established as a crucial biomarker for indicating cancer risk and other oxidative stress-related diseases (Kasai, 1997; Wu et al., 2004; Valavanidis et al., 2009).

\footnotetext{
* Correspondence to: Research Center for Eco-environmental Sciences, Chinese Academy of Sciences, 18 Shuangqing Road, P.O. Box 2871, Beijing 100085, China.

E-mail address: LHGuo@rcees.ac.cn (L.-H. Guo).
}

Living organisms have developed a number of repairing pathways to maintain the integrity of genome. The main strategy for correcting DNA base lesions is base excision repair (BER), which is accurately controlled by certain glycosylases (Sancar, 1996; Lindahl et al., 1997; Krokan et al., 1997). For example, formamidopyrimidine-DNA glycosylase (FPG) operates the excision of 8-oxodGuo in bacterial species (Perlow-Poehnelt et al., 2004; Hamm et al., 2007). The enzyme combines the function of a glycosylase and an endonuclease, thus converting its substrates into single-strand breaks (Tchou et al., 1991; Boiteux et al., 1992). It is well documented that aberrant expression of glycosylases has profound implication in many human diseases (Wilson Iii and Bohr, 2007). Thus, glycosylases have become important biomarkers and potential therapeutic targets for related diseases (Helleday et al., 2008).

Some metal ions have been shown to be carcinogenic to humans and/or experimental animals, but the mechanisms involved in tumor formation have been not resolved yet (Crespo-López et al., 2009; Hartwig, 2013). One frequently discussed mechanism 


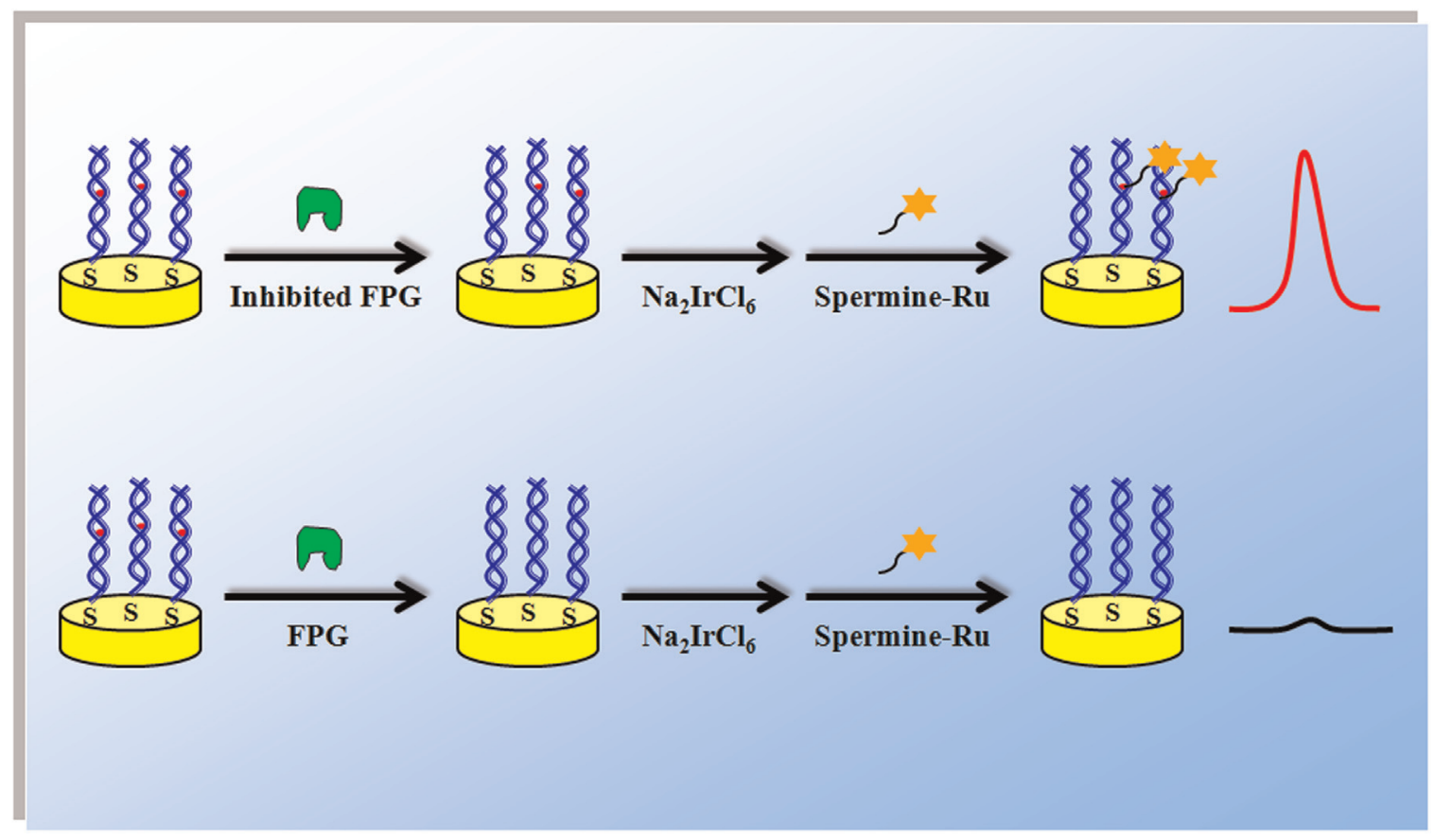

Scheme 1. Schematic diagram of the electrochemiluminescence biosensor for DNA repair enzyme activity analysis.

in metal induced geno-toxicity is the formation of oxidatively damaged DNA products such as 8-oxodGuo and DNA strand breaks (Lloyd and Phillips, 1999). Another mechanism, which has attracted more attention recently, is the inactivation of DNA repair system by the metal ions (Hartwig, 1998; Hartwig et al., 2002). An investigation on human individuals found a correlation between heavy metal exposure and DNA single strand break induction (Hengstler et al., 2003). Inhibition of some isolated DNA repair proteins on their base excision activity by a number of heavy metals were observed (Asmuss et al., 2000a,b; Wang et al., 2006), which was attributed to metal binding with the proteins.

As such, selective determination of 8-oxodGuo, assessment of DNA repair protein activity and evaluation of exogenous chemicals on protein activity are all import issues in molecular carcinogenesis. Over the past decade, a number of analytical methods have been developed for selective quantification of 8-oxodGuo, such as HPLC-MS, HPLC-EC and enzyme-linked immunosorbent assay (ELISA) (Rebelo et al., 2004; Harri et al., 2007; Cooke et al., 2009; Nakagawa et al., 2007). The chromatography-based methods require tedious DNA fragmentation and expensive instrumentations, whereas ELISA suffers from low specificity. Electrochemical sensors offer some distinctive advantages in terms of simplicity, low cost, fast response and miniaturization. Electrochemical detection of several DNA damage products has been studied extensively (Paleček and Fojta, 2001; Rusling et al., 2007; Paleček and Bartošík, 2012; Wu and Guo, 2014). In particular, voltammetric and electrochemiluminescence (ECL) sensors for the detection of 8-oxodGuo were developed by relying on the electrocatalytic reaction between $\mathrm{Os}(\mathrm{bpy})_{2} \mathrm{Cl}^{+}$-polyvinylpyridine and 8-oxodGuo (Dennany et al., 2004; Mugweru et al., 2004). Compared to DNA damage detection, the number of reports on the electrochemical detection of DNA repair is very limited. Pyrimidine dimmers and apurinic sites in DNA were converted to DNA single strand breaks by T4 endonuclease $\mathrm{V}$ and exonuclease III respectively, which were then detected electrochemically (Lao et al., 2005; Havran et al., 2008). In principle, this approach can be used for DNA repair detection. In our previous work, the photoelectrochemical sensor was used briefly for the detection of 8-oxodGuo excision by FPG (Zhang et al., 2012). More recently, real-time electrochemical monitoring of 8-oxodGuo and uracil repair by DNA glycosylases were achieved (McWilliams et al., 2014).

With these in mind, in the present work we developed a DNA biosensor for the detection of 8-oxodGuo lesion repair by FPG enzyme. The sensor was fabricated using a surface-immobilized, 8-oxodGuo containing oligonucleotide monolayer and a bifunctional chemical label for both 8-oxodGuo recognition and electrochemiluminescence signal generation. The developed sensor was then employed in the assessment of metal compounds for their inhibition effect on FPG repair activity so as to explore possible mechanisms of their geno-toxicity (Scheme 1).

\section{Experimental section}

\subsection{Chemicals and materials}

Escherichia coli formamidopyrimidine-DNA glycosylase (FPG) and $1 \times$ NEBuffer 1 (10 mM Bis-Tris-Propane- $\mathrm{HCl}, 10 \mathrm{mM} \mathrm{MgCl}$, $1 \mathrm{mM}$ DTT, pH 7.0) were purchased from New England Biolabs (Ipswich, MA, USA). 6-Mercapto-1-hexanol (MCH), hexaammine ruthenium (III) chloride $\left(\mathrm{Ru}\left(\mathrm{NH}_{3}\right)_{6} \mathrm{Cl}_{3}\right)$, tripropylamine (TPA), tris (2-carboxyethyl) phosphine hydrochloride (TCEP), 4-(4'-methyl$\left[2,2^{\prime}\right]$ bipyridinyl-4-yl)-butyric acid and spermine were from Sigma-Aldrich (St. Louis, MO, USA). Cis-bis (2,2'-bipyridine) dichlororuthenium $\left(\mathrm{Ru}(\mathrm{bpy})_{2} \mathrm{Cl}_{2}\right.$ ) was purchased from Alfa Aesar (Ward Hill, MA, USA). Oligonucleotides with 25 bases containing one 8-oxodGuo were purchased from Takara Bio Inc. (Otsu, Japan). The sequence was 5'-GGA CTG /8-oxodGuo/GA GGA GAT GGG GGA GGA G-3' (target DNA). The control and complementary oligonucleotides were purchased from Sangon Inc. (Shanghai, China). The sequences were 5'-GGA CTG GGA GGA GAT GGG GGA GGA G-3' (control DNA, no lesion) and 5'-SH-C6-CTC CTC CCC CAT CTC CTC CCA GTC C-3' (complementary DNA thiolated at 5' terminus with a C6 spacer). All solutions were prepared with high-purity water from a Millipore Milli-Q (Biocel, Merck, U.S.A.). Buffers used in this work were as follow: DNA hybridization solution $(2 \times$ SSC buffer $)$, $0.3 \mathrm{M}$ sodium chloride, $30 \mathrm{mM}$ sodium citrate, $\mathrm{pH}$ 7.0; DNA immobilization buffer (I-buffer), $10 \mathrm{mM}$ Tris-HCl, $1 \mathrm{mM}$ EDTA, $1.0 \mathrm{M}$ 
$\mathrm{NaCl}, 1 \mathrm{mM}$ TCEP, $\mathrm{pH}$ 8.0; buffer for electrochemiluminescence measurement (E-buffer), 0.2 M TPA, $0.1 \mathrm{M} \mathrm{NaCl}, 0.15 \mathrm{M} \mathrm{PB}, 0.1 \%$ TX-100, pH 7.4. TCEP was used to cleave disulfides and was prepared on the day of use.

\subsection{Spermine-Ru synthesis}

Spermine was linked to 4-(4'-methyl-[2,2'] bipyridinyl-4-yl)butyric acid through the DCC/NHS reaction. The obtained crude product was denoted as Compound 3 (1.188 g). Spermine-Ru was then synthesized according to the previously reported procedure (Sullivan et al., 1978). Briefly, a mixed solution of $15 \mathrm{~mL}$ methanol, $10 \mathrm{~mL}$ water, $1.188 \mathrm{~g}(0.0027 \mathrm{~mol})$ Compound 3, and $1.392 \mathrm{~g}$ $(0.003 \mathrm{~mol}) \mathrm{Ru}(\mathrm{bpy})_{2} \mathrm{Cl}_{2}$ was refluxed for $6 \mathrm{~h}$ under nitrogen atmosphere. After refluxing, the solution was cooled to room temperature, and $10 \mathrm{~mL}$ saturated sodium hexafluoro-phosphate was added to precipitate the product. The obtained earthy yellow precipitate was purified by re-crystallization with acetone and ether in $75 \%$ yield $(2.2 \mathrm{~g})$. The final product was then certified on a quadrupole-time of flight mass spectrometer (micrOTOF QII, Bruker, Germany) equipped with an electrospray ionization (ESI) source in positive-ion mode over a mass scan range of 50-1000 m/ $z$. The reactivity of spermine-Ru with 8 -oxodGuo was validated by denaturing polyacrylamide gel electrophoresis (PAGE, 20\% concentration, $5 \%$ cross-link).

\subsection{Electrode modification with double-stranded DNA}

Oligonucleotide hybridization was performed in $2 \times$ SSC buffer on a Biometra T-Gradient thermocycler (Goettingen, Germany). The mixture solution of the two oligonucleotides ( $100 \mu \mathrm{M}$ each) was heated to $95{ }^{\circ} \mathrm{C}$ and slowly cooled down to room temperature. The concentration of ds-DNA was then determined by its absorbance at $260 \mathrm{~nm}$ on an UV-vis spectrophotometer (Agilent Technologies, Santa Clara, CA). The prepared ds-DNA solution $(50 \mu \mathrm{M})$ was stored at $4^{\circ} \mathrm{C}$.

Gold electrode modification was performed according to a reported procedure (Zhang et al., 2007). Briefly, a gold electrode (2 mm in diameter, $\mathrm{CH}$ Instruments Inc. Austin, TX, USA,) was first polished on a microcloth with $0.05 \mu \mathrm{m}$ alumina suspension and followed by $10 \mathrm{~min}$ sonication in Milli-Q water. Then, electrochemical cleaning was performed in $0.5 \mathrm{M} \mathrm{H}_{2} \mathrm{SO}_{4}$ by applying a positive potential of $2.0 \mathrm{~V}$ for $5 \mathrm{~s}$, followed by a negative potential of $-0.35 \mathrm{~V}$ for $10 \mathrm{~s}$. Next, repetitive CV scans were conducted within a potential window between -0.3 and $1.55 \mathrm{~V}$ at a scan rate of $4 \mathrm{~V} / \mathrm{s}$ (10 cycles) in $0.5 \mathrm{M} \mathrm{H}_{2} \mathrm{SO}_{4}$. Finally, the electrode was rinsed with Milli-Q water and dried in a $\mathrm{N}_{2}$ stream.

The immobilization of the ds-DNA to the gold electrode was performed by applying $4 \mu \mathrm{L}$ of $2.0 \mu \mathrm{M}$ ds-DNA on a freshly cleaned gold electrode surface and incubated for $48 \mathrm{~h}$ at room temperature. The electrode was then washed with plenty of Milli-Q water to remove the nonspecifically adsorbed ds-DNA. Subsequently, the electrode was treated with $10 \mathrm{mM} \mathrm{MCH}$ for $2 \mathrm{~h}$. Cyclic voltammetry measurement in $50 \mu \mathrm{M} \mathrm{Ru}\left(\mathrm{NH}_{6}\right)_{3}{ }^{3+} / 10 \mathrm{mM}$ Tris buffer was conducted to verify DNA immobilization on Au.

\subsection{8-OxodGuo labeling and enzymatic cleavage}

The ds-DNA (containing 8-oxodGuo) coated electrode was incubated with $4 \mu \mathrm{L}$ of $10 \mu \mathrm{M}$ spermine-Ru in PBS for $30 \mathrm{~min}$ at $25{ }^{\circ} \mathrm{C}$. An aqueous solution of $\mathrm{Na}_{2} \mathrm{IrCl}_{6}(0.6 \mathrm{mM}, 1 \mu \mathrm{L})$ was then added into the above solution, and the electrode was incubated for an additional $30 \mathrm{~min}$ (Xue and Greenburg, 2007; Zhang et al., 2012). The electrode was washed thoroughly before ECL measurement. It is possible that spermine-Ru (II) could be oxidized by $\mathrm{Na}_{2} \mathrm{IrCl}_{6}$ to spermine-Ru (III) during the labeling process. But this should not pose any problem, since in the ECL measurement any spermine-Ru (III) will be reduced to spermine-Ru (II) at the starting potential.

In FPG activity assay, the ds-DNA (containing 8-oxodGuo) coated electrode was first incubated with $5 \mu \mathrm{L}$ FPG in $1 \times$ NEBuffer 1 at $37^{\circ} \mathrm{C}$ for $1 \mathrm{~h}$ to excise 8 -oxoGuo lesions in the immobilized dsDNA film. After washing with Milli-Q water and drying, labeling of 8-oxodGuo with spermine-Ru was carried out as described above. FPG is fairly unstable. Therefore, same lot of FPG solution was used for each set of experiments.

\subsection{ECL measurement}

ECL measurement was performed on a $\mathrm{CHI}$ 660b electrochemistry analyzer ( $\mathrm{CH}$ Instruments, Austin, TX, USA) by placing the DNA-modified gold electrode in E-buffer, using a Pt flag counter electrode and a $\mathrm{Ag} / \mathrm{AgCl}(3 \mathrm{M} \mathrm{KCl})$ reference electrode. The ECL signal was collected with an H9306-03 photomultiplier tube (PMT, Hamamatsu, Japan) placed directly beneath the transparent electrochemical cell. Both the cell and PMT were enclosed in a light-tight box. The voltage output of the PMT was sent to the auxiliary signal recording port on the $\mathrm{CHI} 660 \mathrm{~b}$ analyzer.

\section{Result and discussion}

\subsection{An electrochemiluminescence biosensor for 8-oxodGuo quantification}

Reaction of 8-oxodGuo with spermine or other diamines under oxidative condition is well-established. According to the report, the yield of DNA-spermine adducts can reach $75 \%$ from B-form self-complementary ds-DNA (Hosford et al., 2004). In the current work, we designed a bifunctional probe, spermine-Ru, for selective electrochemiluminescence detection of 8-oxodGuo. The probe is a conjugate composed of two parts. One part is spermine, which is used to react specifically with 8-oxodGuo under oxidative conditions. The other part is a ruthenium tris(bipyridine) derivative acting as an electrochemiluminescence signal reporter. The advantage of this bifunctional probe is that it requires only one step reaction to label 8-oxodGuo, as opposed to the two-step reaction in our previous work (Zhang et al., 2012). PAGE experiment was first conducted to verify the reactivity between the probe and 8 -oxodGuo. In the experiment, we tested two oligonucleotide duplexes with the same base sequence, except for Duplex 1 containing one 8-oxodGuo lesion. As shown in Fig. S3, a new lag band was observed after incubation of Duplex 1 with excessive spermine- $\mathrm{Ru}$ in a $\mathrm{Na}_{2} \mathrm{IrCl}_{6}$ solution. This indicates that the new probe covalently captured 8-oxodGuo lesion in Duplex 1 through a onestep reaction.

To develop the electrochemiluminescence sensor, DNA modified surface was prepared on a gold electrode by self-assembly of the oligonucleotide duplexes derivatized at the 5'-end with a thiol-terminated aliphatic linker. The electrode was then reacted with $\mathrm{MCH}$ to block the empty sites on the surface and to obtain a well-aligned ds-DNA monolayer. After that, cyclic voltammetry (CV) measurement was carried out in a $\mathrm{Ru}\left(\mathrm{NH}_{6}\right)_{3}{ }^{3+}$ solution. In Fig. S4, there were two pairs of redox peaks in the cyclic voltammogram: one at $\sim-0.13 \mathrm{~V}$ due to $\mathrm{Ru}\left(\mathrm{NH}_{6}\right)_{3}{ }^{3+}$ free in solution, and the other at $\sim-0.29 \mathrm{~V}$ ascribed to $\mathrm{Ru}\left(\mathrm{NH}_{6}\right)_{3}{ }^{3+}$ bound electrostatically to the DNA backbone (Lao et al., 2005). The cyclic voltammogram revealed that the $\mathrm{DNA} / \mathrm{MCH}$ film on the gold electrode was assembled successfully.

After DNA film assembly, 8-oxodGuo in the film was labeled with the spermine-Ru probe through a one-step reaction, using $\mathrm{Na}_{2} \mathrm{IrCl}_{6}$ as the oxidant. After a thorough wash, the electrode was 


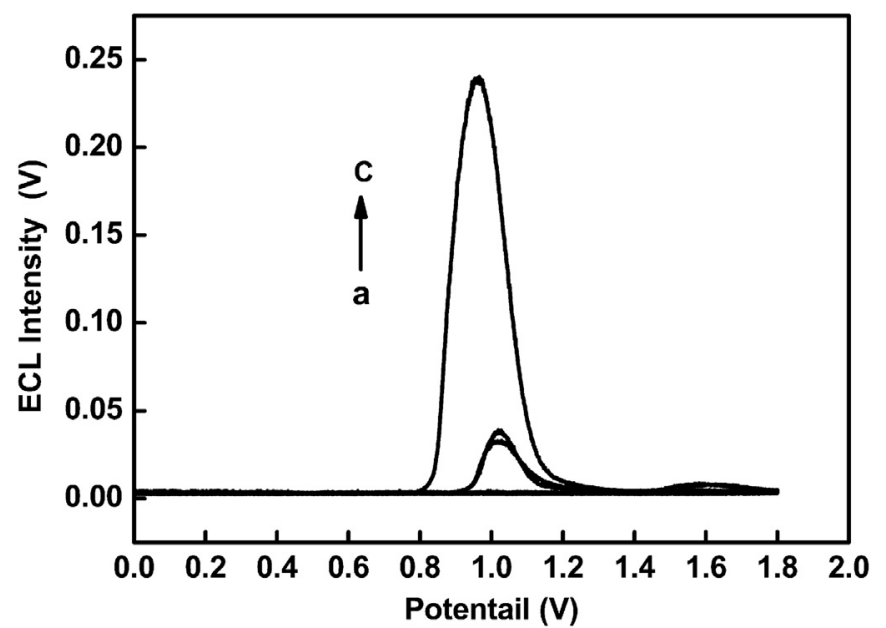

Fig. 1. ECL response curves of (a) Duplex 1 film reacted with spermine-Ru in the absence of any oxidant, (b) Duplex 2 film reacted with spermine-Ru in a $\mathrm{Na}_{2} \mathrm{IrCl}_{6}$ solution, and (c) Duplex 1 film reacted with spermine-Ru in a $\mathrm{Na}_{2} \mathrm{IrCl}_{6}$ solution. The ECL measurement was performed in $100 \mathrm{mM}$ TPA, $150 \mathrm{mM}$ phosphate, pH 7.4.

placed in the E-buffer for ECL measurement. As depicted in Fig. 1, an electrochemiluminescence peak occurred at approximately $1.1 \mathrm{~V}$ for spermine-Ru labeled Duplex $1 \mathrm{film}$. In comparison, the ECL signal of Duplex 2 containing no 8-oxodGuo lesion was much lower, and is probably due to the non-specifically adsorbed probe. Without the use of $\mathrm{Na}_{2} \mathrm{IrCl}_{6}$ as the oxidant, even Duplex 1 did not produce much ECL after labeling. The ECL results are consistent with those of PAGE experiments, and further verify the selective covalent linkage of spermine-Ru with 8-oxodGuo lesion sites under oxidative condition.

The ECL intensity was found to be highly dependent on the amount of 8-oxodGuo lesions on the electrode surface. Keeping the total oligonucleotide concentration constant, a series of mixture solutions containing different ratios of Duplex 1 and Duplex 2 were prepared for oligonucleotide immobilization. As the total duplex concentration was fixed, the amount of oligonucleotides immobilized on the gold electrode was assumed to be the same regardless of the mixture solutions used. Increasing the fraction of Duplex 2 in the mixture should therefore reduce the surface coverage of Duplex 1, and consequently 8-oxodGuo. As illustrated in Fig. 2, the electrochemiluminescence decreased progressively as

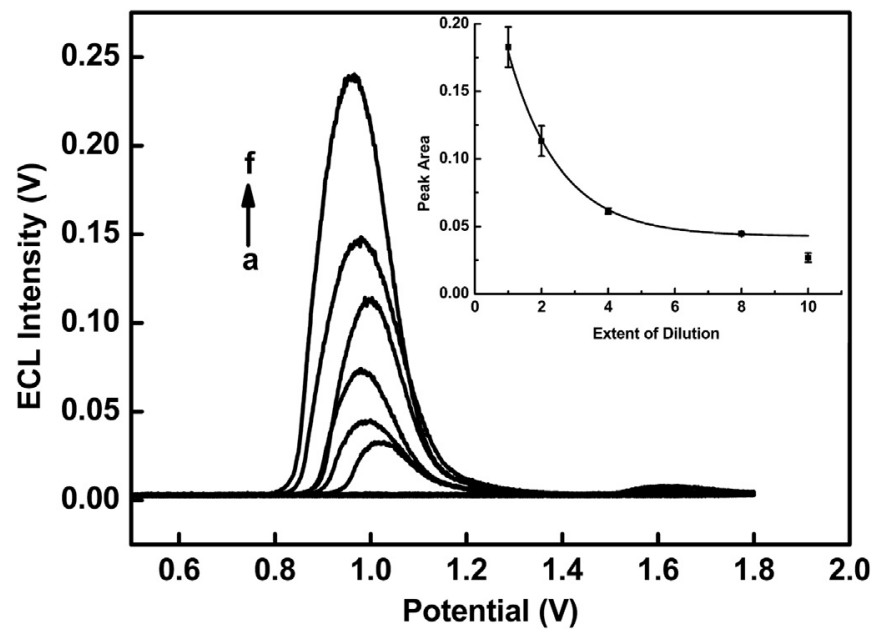

Fig. 2. ECL response curves of spermine-Ru labeled Duplex 1 films diluted with different ratios of Duplex 2 (from a to f: Duplex 2 only, 9:1, 7:1, 3:1, 1:1, Duplex 1 only). Inset is a plot of the background-corrected ECL intensity as a function of the dilution ratio. Error bars represent the standard deviation of 3 replicate electrodes.
Duplex 1 in the mixture solution was diluted with Duplex 2. At 10 times dilution ratio, the signal was still above the background, which corresponds to 18 -oxodGuo lesion in 500 normal bases. This detection sensitivity is very similar to the one reported previously for the photoelectrochemical sensor (Zhang et al., 2012), but the operation of the current sensor is simplified. Unfortunately the calibration curve is not linear, and linear fitting is therefore not possible.

\subsection{FPG activity determination}

After the ECL response of spermine-Ru labeled 8-oxodGuo was established, its application for the assessment of DNA repair enzyme activity was explored. PAGE experiments were first conducted to verify the activity of FPG toward the excision of 8-oxodGuo lesions in the oligonucleotide duplexes. As illustrated in Fig. S5, the intact Duplex 1 sample displayed three bands in the PAGE image, with the major one at the bottom (Lane 1). After reacting with FPG, the two darker bands almost disappeared. Instead, three highly visible new bands with shorter lengths emerged. By comparison, the image of Duplex 2 after FPG treatment (Lane 5) was almost identical to the intact Duplex 1. The emergence of shorter oligonucleotides in the image was due to the excision of 8-oxodGuo and subsequent double-strand breaks of Duplex 1 by FPG. The electrophoresis results proved that FPG protein was highly efficient in repairing 8-oxodGuo lesions in the oligonucleotides.

Next, excision of 8-oxodGuo by FPG was tested on electrode surface. After immobilization of Duplex 1 film on gold electrodes, it was reacted with different concentrations of FPG $(0-4 \mathrm{U} / \mu \mathrm{L})$ and followed by labeling with spermine- $\mathrm{Ru}$ in $\mathrm{Na}_{2} \mathrm{IrCl}_{6}$ solution. It was found that the ECL intensity of labeled Duplex 1 decreased significantly with increasing FPG concentrations. This is because FPG protein excised 8-oxodGuo in Duplex 1 and removed it from the electrode surface, thus resulting in less spermine-Ru labels on the electrode and reduced ECL signal. As illustrated in Fig. 3, an inverse relationship between ECL intensity and FPG concentration was observed in a range from 0 to $4.0 \mathrm{U} / \mu \mathrm{L}$, demonstrating that the ECL biosensor could be used for FPG activity assay.

\subsection{Influence of metal compounds on FPG activity}

As discussed in the Introduction section, the DNA repair

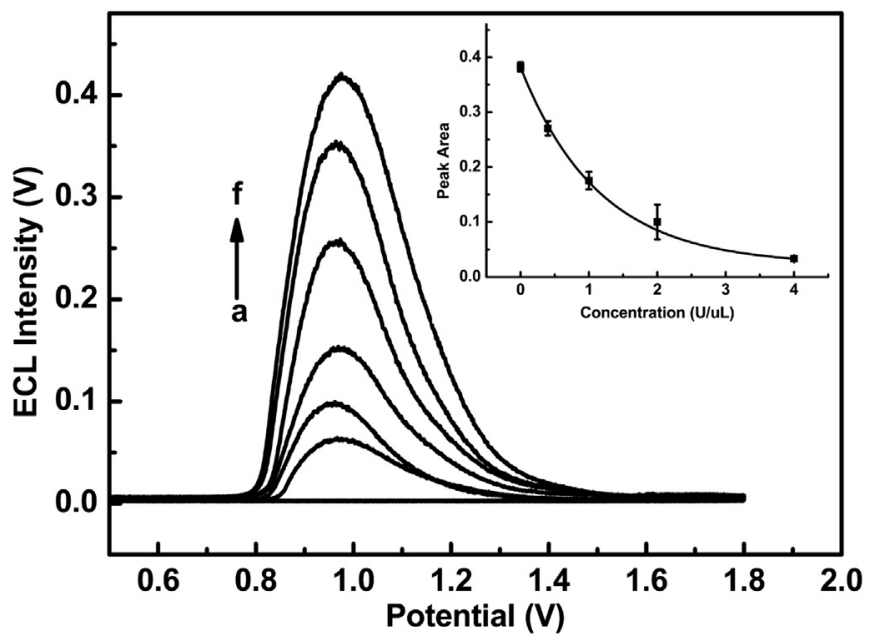

Fig. 3. ECL response curves of spermine-Ru labeled Duplex 1 films after incubation with different concentrations of FPG for $1 \mathrm{~h}$. (a) control, spermine-Ru labeled Duplex 1 without the treatment of $\mathrm{Na}_{2} \mathrm{IrCl}_{6}$, (b) $4 \mathrm{U} / \mu \mathrm{L} \mathrm{FPG}$, (c) $2 \mathrm{U} / \mu \mathrm{L} \mathrm{FPG}$, (d) $1 \mathrm{U} / \mu \mathrm{L}$ FPG, (e) $0.5 \mathrm{U} / \mu \mathrm{L}$ FPG, and (f) $0 \mathrm{U} / \mu \mathrm{L}$ FPG. Inset is a plot of the background-corrected $\mathrm{ECL}$ intensity as a function of FPG concentration. Error bars represent the standard deviation of 3 replicate electrodes. 

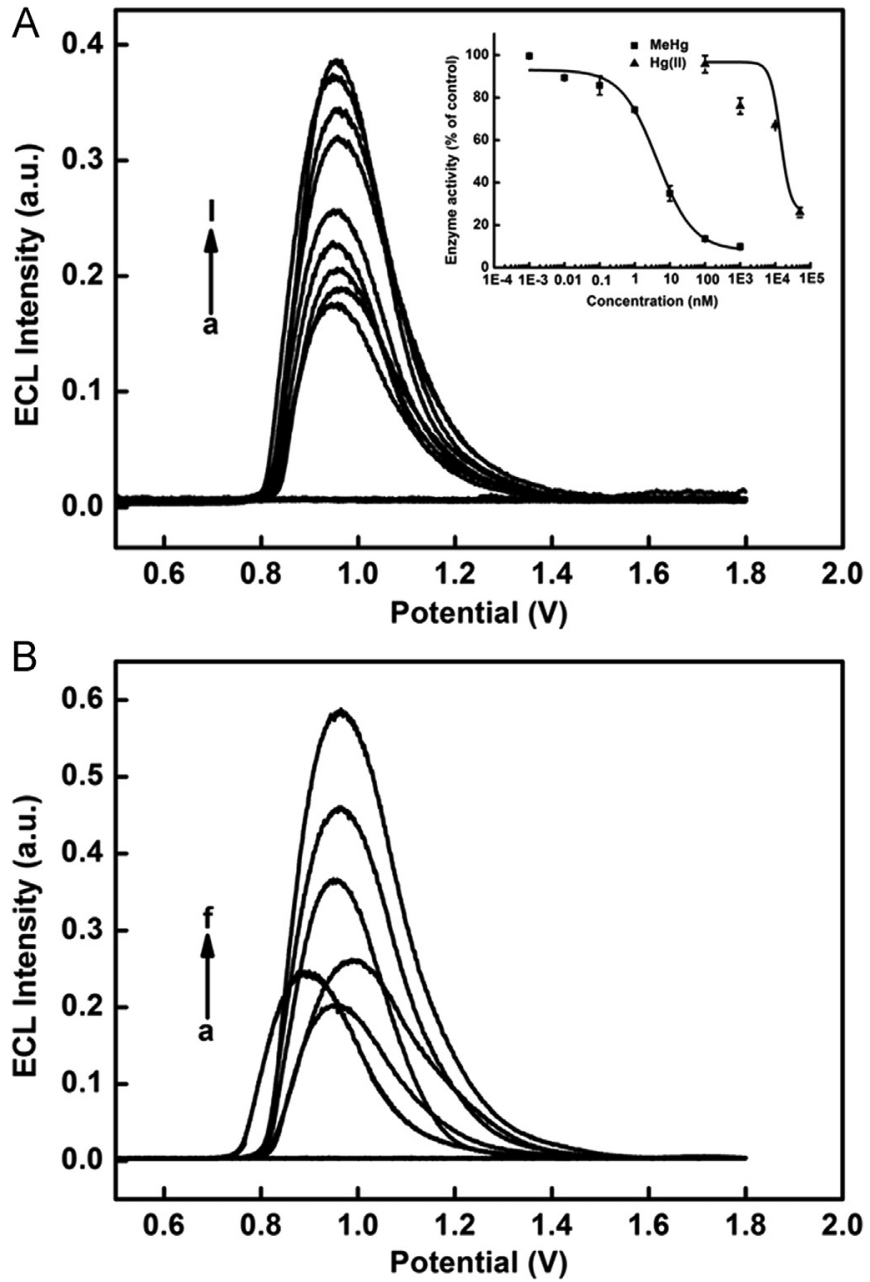

Fig. 4. ECL response of spermine-Ru labeled Duplex 1 films after incubation with $4 \mathrm{U} / \mu \mathrm{L}$ FPG for $1 \mathrm{~h}$. (A) FPG was pre-incubated with different concentrations of MeHg (a) 0 pM, (b) 1 pM, (c) 10 pM, (d) 100 pM, (e) $1 \mathrm{nM}$, (f) $10 \mathrm{nM}$, (g) $100 \mathrm{nM}$, (h) $1000 \mathrm{nM}$, (I) control, without FPG, for $1 \mathrm{~h}$ at $37^{\circ} \mathrm{C}$. (B) FPG was pre-incubated with different concentrations of $\mathrm{Hg}^{2+}$ (a) $0 \mu \mathrm{M}$, (b) $0.1 \mu \mathrm{M}$, (c) $1 \mu \mathrm{M}$, (d) $10 \mu \mathrm{M}$, (e) $50 \mu \mathrm{M}$, (f) control, without FPG, for $1 \mathrm{~h}$ at $37^{\circ} \mathrm{C}$. Inset is a plot of the relative activity of FPG as a function of metal concentration. Values represent the mean $\pm S$. E., $n=3$.

capability of FPG is subject to inactivation by inhibitors. For a geno-toxic chemical, it may either act directly on DNA molecules and produce various DNA damage products, or exert its toxicity indirectly by inhibiting the activity of DNA repair enzymes such as FPG. Therefore, the FPG activity sensor established above can be used to screen chemicals for their inhibition effect and potential geno-toxicity. Six common heavy metal ions and metal compound, $\mathrm{Cd}^{2+}, \mathrm{Pb}^{2+}, \mathrm{Ni}^{2+}, \mathrm{Co}^{2+}, \mathrm{Hg}^{2+}$ and $\mathrm{MeHg}(\mathrm{II})$, were evaluated by the sensor. In the experiment, FPG was first incubated with a metal ion at $37^{\circ} \mathrm{C}$ for $1 \mathrm{~h}$, and then added to the Duplex $1 \mathrm{film}$ on the electrode to carry out the excision reaction. After labeling, ECL signal was measured. The results were summarized in Fig. 4A and B. Although the ECL intensity of labeled 8-oxodGuo was low after excision by FPG, the signal recovered gradually with addition of $\mathrm{Hg}^{2+}$ or $\mathrm{MeHg}$ (II), as demonstrated in Fig. 4. In a control experiment, the Duplex 1 film was incubated with either $50 \mu \mathrm{M}$ $\mathrm{Hg}^{2+}$ or $1.0 \mu \mathrm{M}$ MeHg (II), but no FPG. It was found that the metal ion alone did not have any impact on ECL signal (Fig. S6). These results indicated that the two mercury compounds inhibited FPG activity, leaving more of the 8-oxodGuo lesions on the electrode surface which in turn produced higher ECL signal after labeling.

Relative activity of FPG in the presence of a metal ion can be

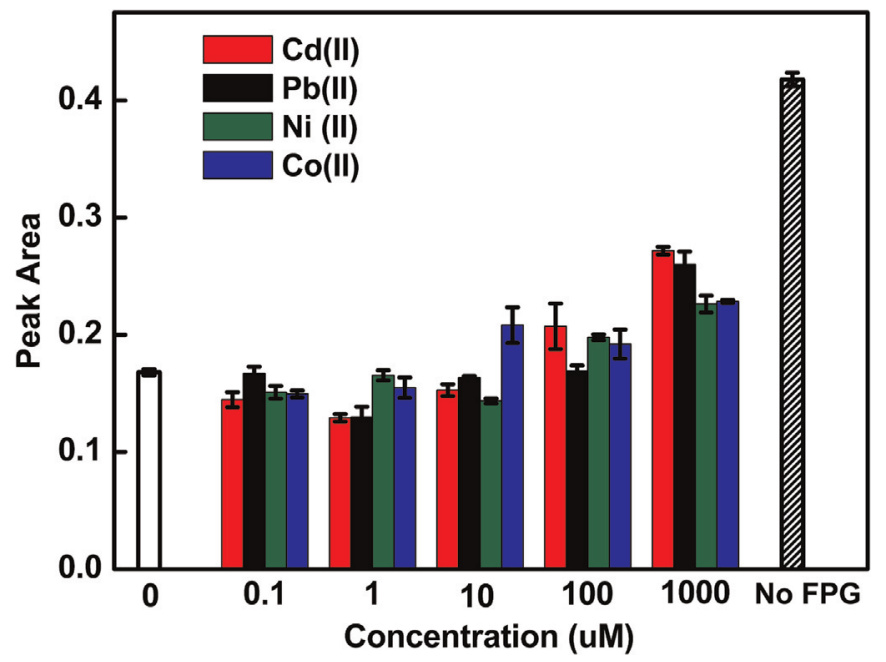

Fig. 5. The ECL signal intensity of Duplex 1 films after repair by $4 \mathrm{U} / \mu \mathrm{L}$ FPG. FPG was pre-incubated with different concentrations of the respective metal compounds at the indicated concentrations for $1 \mathrm{~h}$ at $37^{\circ} \mathrm{C}$.Error bars represent the standard deviation of three replicate electrodes.

estimated from the ECL intensity by using the following equation,

$\mathrm{RA}=\frac{I-I_{0}}{I_{1}-I_{0}}$

where RA is the relative activity of FPG, $I_{1}$ is the ECL intensity without FPG, $I_{0}$ is the ECL intensity with FPG but no metal ion, and $I$ is the ECL intensity with both FPG and a metal ion at a given concentration. A plot of RA versus the metal concentration yielded a sigmoidal curve (Fig. 4A, inset) which was typical of an inhibition effect. The dose-response curve was then fitted with the Hill equation (Copeland, 2003; Nau et al., 2009) to obtain an $\mathrm{IC}_{50}$ (the metal concentration at which FPG activity is inhibited to $50 \%$ ). The $\mathrm{IC}_{50}$ values were found to be about $14.0 \mu \mathrm{M}$ and $4.3 \mathrm{nM}$ respectively for $\mathrm{Hg}$ (II) and MeHg.

As for $\mathrm{Cd}^{2+}, \mathrm{Pb}^{2+}, \mathrm{Ni}^{2+}$ and $\mathrm{Co}^{2+}$, these metal ions did not show any appreciable effect on ECL signal until they reached a concentration of $100 \mu \mathrm{M}$ or higher (Fig. 5), demonstrating much less inhibition on FPG activity. Hartwig et al. investigated the interference of a number of heavy metals on the activity of isolated FPG, using a 10K base pair super-coiled circular DNA as FPG substrate and electrophoresis for DNA analysis. They found that $\mathrm{Ni}(\mathrm{II})$, $\mathrm{Co}(\mathrm{II}), \mathrm{As}(\mathrm{III})$ and $\mathrm{Pb}(\mathrm{II})$ did not show any effect on FPG, but $\mathrm{Cd}(\mathrm{II})$, $\mathrm{Cu}(\mathrm{II})$ and $\mathrm{Hg}(\mathrm{II})$ inhibited FPG activity substantially, with $\mathrm{Hg}(\mathrm{II})$ being the strongest inhibitor (Asmuss et al., 2000a,b). Our study also identified $\mathrm{Hg}(\mathrm{II})$ as the strongest inhibitor among the five metal ions, followed by $\mathrm{Cd}(\mathrm{II})$. In general, our results agreed reasonably well with the previous studies.

More importantly, based on the obtained $\mathrm{IC}_{50}$ values we also found that $\mathrm{MeHg}$ was about 3000 times more potent that $\mathrm{Hg}^{2+}$ in FPG inhibition. It is well known that several $\mathrm{Hg}$ compounds induce neurotoxicity, and $\mathrm{MeHg}$ is more toxic than inorganic mercury (Fretham et al., 2012). A commonly studied mechanism of $\mathrm{Hg}$ toxicity is the generation of reactive oxygen species and resulting macromolecular damage and alteration of signal transduction pathways (Crespo-López et al., 2009). A comparison of genotoxicity between inorganic and organic mercury compounds revealed that $\mathrm{MeHg}$ induced DNA damage at significantly lower concentrations than inorganic mercury (Ogura et al., 1996). Our study was the first report on the inhibition effect of organic mercury on FPG. The result might suggest that interference on the DNA repair system could be another mechanism for the high toxicity of $\mathrm{MeHg}$.

In FPG protein, DNA binding is carried out by a single zinc finger domain in the C-terminal region, where zinc is complexed 
with four cysteines (Cys 244, Cys 247, Cys 264 and Cys 267). Substitution of any cysteine in the 'zinc finger' destroys its DNA binding capacity as well as DNA repairing function. Mercury has a very high affinity for sulfur-containing anions, particularly the thiol (-SH) groups on cysteine residues (Valko et al., 2005; Hultberg et al., 2001). Interactions of mercury with sulfhydryl groups in albumin, metallothionein, glutathione, and cysteine have been demonstrated (McGoldrick et al., 2003). FPG inactivation in the presence of inorganic or organic $\mathrm{Hg}$ might also result from their interactions with sulfhydryl-containing residues in the protein.

\section{Conclusion}

To conclude, a novel electrochemiluminescence biosensor has been developed for 8-oxodGuo quantification and FPG activity assay. The sensor employed a newly synthesized probe with both 8-oxodGuo recognition and ECL generation functions, thus greatly simplifying sensor preparation. The ECL intensity was found to be related to the amount of 8-oxodGuo on the sensor surface, with a detection limit of 18 -oxodGuo lesion in 500 normal bases. The sensor was employed successfully for FPG activity analysis and investigation of metal ions for their inhibition effect on FPG activity. With its low cost fabrication, simple operation and rapid turnaround, this new sensor possesses significant advantages over conventional DNA repair activity assays. It can be used for the rapid screening of chemicals for their inhibition effect on DNA repair systems and exploration of molecular mechanisms of genotoxic chemicals.

\section{Acknowledgments}

This work was supported by the National Basic Research Program of China (2011CB936001), Chinese Academy of Sciences (XDB14040100), and the National Natural Science Foundation of China (21375143 and 21321004).

\section{Appendix A. Supplementary material}

Supplementary data associated with this article can be found in the online version at http://dx.doi.org/10.1016/j.bios.2015.02.037.

\section{References}

Andrew, R.C., Maria, D., Catherine, M.G., Rudolf, S., 1996. Environ. Health Perspect. 104, 465-469.

Asmuss, M., Mullenders, L.H.F., Eker, A., Hartwig, A., 2000a. Carcinogenesis 21, 2097-2104.

Asmuss, M., Mullenders, L.H.F., Hartwig, A., 2000b. Toxicol. Lett. 112-113, 227-231. Boiteux, S., Gajewski, E., Laval, J., Dizdaroglu, M., 1992. Biochemistry 31, 106-110. Cheng, K.C., Cahill, D.S., Kasai, H., Nishimura, S., Loeb, L.A., 1992. J. Biol. Chem. 267, 166-172.

Cooke, M., Barregard, L., Mistry, V., Potdar, N., Rozalski, R., Gackowski, D., Siomek,
A., Foksinski, M., Svoboda, P., Kasai, H., Konje, J., Sallsten, G., Evans, M.D., Olinski, R., 2009. Biomarkers 14, 103-110.

Cooke, M.S., Evans, M.D., Dizdaroglu, M., Lunec, J., 2003. Faseb J. 17, 1195-1214.

Copeland, R.A., 2003. Anal. Biochem. 320, 1-12.

Crespo-López, M.E., Macêdo, G.L., Pereira, S.I.D., Arrifano, G.P.F., Picanço-Diniz, D.L. W., Nascimento, J.L.M.D., Herculano, A.M., 2009. Pharmacol. Res. 60, 212-220. Dennany, L., Forster, R.J., White, B., Smyth, M., Rusling, J.F., 2004. J. Am. Chem. Soc $126,8835-8841$.

Fretham, S.J.B., Caito, S., Martinez-Finley, E.J., Aschner, M., 2012. Toxicol. Res. 1, 32-38.

Halliwell, B., 1991. Am. J. Med. 91, S14-S22.

Hamm, M.L., Gill, T.J., Nicolson, S.C., Summers, M.R., 2007. J. Am. Chem. Soc. 129, 7724-7725.

Harri, M., Kasai, H., Mori, T., Tornaeus, J., Savela, K., Peltonen, K., 2007. J. Chromatogr. B 853, 242-246.

Hartwig, A., 1998. Toxicol. Lett. 102-103, 235-239.

Hartwig, A., 2013. Free Radic. Biol. Med. 55, 63-72.

Hartwig, A., Asmuss, M., Ehleben, I., Herzer, U., Kostelac, D., Pelzer, A., Schwerdtle, T., Bürkle, A., 2002. Environ. Health Perspect. 110, 797-799.

Havran, L., Vacek, J., Cahová, K., Fojta, M., 2008. Anal. Bioanal. Chem. 391, $1751-1758$

Helleday, T., Petermann, E., Lundin, C., Hodgson, B., Sharma, R.A., 2008. Nat. Rev. Cancer 8, 193-204.

Hengstler, J.G., Bolm-Audorff, U., Faldum, A., Janssen, K., Reifenrath, M., Götte, W. Jung, D., Mayer-Popken, O., Fuchs, J., Gebhard, S., Bienfait, H.G., Schlink, K., Dietrich, C., Faust, D., Epe, B., Oesch, F., 2003. Carcinogenesis 24, 63-73.

Hosford, M.E., Muller, J.G., Burrows, C., 2004. J. Am. Chem. Soc. 126, 9540-9541. Hultberg, B., Andersson, A., Isaksson, A., 2001. Toxicology 156, 93-100. Jackson, A.L., Loeb, L.A., 2001. Mutat. Res.-Fundam. Mol. M 477, 7-21.

Kasai, H., 1997. Mutat. Res.-Rev. Mutat. 387, 147-163.

Krokan, H.E., Standal, R., Slupphaug, G., 1997. Biochem. J. 325, 1-16.

Lao, R.J., Song, S.P., Wu, H.P., Wang, L.H., Zhang, Z.Z., He, L., Fan, C.H., 2005. Anal. Chem. 77, 6475-6480.

Lindahl, T., Karran, P., Wood, R.D., 1997. Curr. Opin. Genet. Dev, 7, 158-169.

Lloyd, D.R., Phillips, D.H., 1999. Mutat. Res.-Fundam. Mol. M 424, 23-36.

McGoldrick, T., Lock, E., Rodilla, V., Hawksworth, G., 2003. Arch. Toxicol. 77, 365-370.

McWilliams, M.A., Anka, F.H., Balkus, K.J., Slinker, J.D., 2014. Biosens. Bioelectron. 54, 541-546.

Mugweru, A., Wang, B., Rusling, J., 2004. Anal. Chem. 76, 5557-5563.

Nakagawa, O., Ono, S., Li, Z., Tsujimoto, A., Sasaki, S., 2007. Angew. Chem. Int. Ed. 119, 4584-4587.

Nau, W.M., Ghale, G., Hennig, A., Bakirci, H., Bailey, D.M., 2009. J. Am. Chem. Soc. 131, 11558-11570.

Ogura, H., Takeuchi, T., Morimoto, K., 1996. Mutat. Res.-Rev. Genet. Toxicol. 340, 175-178.

Paleček, E., Bartošík, M., 2012. Chem. Rev. 112, 3427-3481.

Paleček, E., Fojta, M., 2001. Anal. Chem. 73, 74, A-83 A.

Perlow-Poehnelt, R.A., Zharkov, D.O., Grollman, A.P., Broyde, S., 2004. Biochemistry 43, 16092-16105.

Rebelo, I.A., Piedade, J.A.P., Oliveira-Brett, A.M., 2004. Talanta 63, 323-331.

Rusling, J.F., Hvastkovs, E.G., Schenkman, J.B., 2007. Curr. Opin. Genet. Dev. 10, 67-73.

Sancar, A., 1996. Annu. Rev. Biochem. 65, 43-81.

Sullivan, B.P., Salmon, D.J., Meyer, T.J., 1978. Inorg. Chem. 17, 3334-3341.

Tchou, J., Kasai, H., Shibutani, S., Chung, M.H., Laval, J., Grollman, A.P., Nishimura, S. 1991. Proc. Natl. Acad. Sci. USA 88, 4690-4694.

Valavanidis, A., Vlachogianni, T., Fiotakis, C., 2009. J. Environ. Sci. Health C 27, 120-139.

Valko, M., Izakovic, M., Mazur, M., Rhodes, C., Telser, J., 2004. Mol. Cell. Biochem. 266, 37-56.

Valko, M. Morris, H. Cronin, MTD. 2005. Curr Med Chem. 12, 1161-1208.

Wang, P., Guliaev, A.B., Hang, B., 2006. Toxicol. Lett. 166, 237-247.

Wilson Iii, D.M., Bohr, V.A., 2007. DNA Repair 6, 544-559.

Wu, L.L., Chiou, C.C., Chang, P.Y., Wu, J.T., 2004. Clin. Chim. Acta. 339, 1-9.

Wu, Y.P., Guo, L.-H., 2014. Prog. Chem. 26, 1-9.

Xue, L., Greenburg, M.M., 2007. J. Am. Chem. Soc. 129, 7010-7011.

Zhang, B., Guo, L.-H., Greenberg, M.M., 2012. Anal. Chem. 84, 6048-6053.

Zhang, J., Song, S., Wang, L., Pan, D., Fan, C., 2007. Nat. Protoc. 2, 2888-2895. 